\title{
Impediments to Civil Registration: The case of Somali Regional State in Ethiopia*
}

\author{
Abdirahman A. Muhumad ${ }^{1}$ []
}

\begin{abstract}
Civil registration is the best source of demographic data, compared to population census and sample surveys, as the last two are not continuous. It is defined as the continuous, permanent, compulsory and universal recording of the occurrence and characteristics of vital events pertaining to the population, as provided through decree or regulation in accordance with the legal requirements of each country. Civil registration systems are basic components of good governance, essential for the production of vital statistics, and many other health and population indicators. However, civil registration systems and data are at their infant stages, if non-existent. in many developing countries. Sub-saharan African nations have the largest number of unregistered vital events.

Using interviews, office reports and related documents, the study found that little progress has been made on civil registration in the Somali region due to a number of challenges that affect the system. Financial, human resource and logistical challenges, lack of political priority, lack of value for registration, low awareness, the registration process and the mobile nature of pastoralists are among the key challenges that hinder the progress.

The study proposes legal reforms, political commitment and strengthening coordination (interoperability) between and among the key stakeholders to improve the functionality of the system.

\section{Keywords}

Civil registration, Vital events registration, Somali region, Impediments/challenges, Functional civil registration system
\end{abstract}

\footnotetext{
* Somali Regional State is one of the nine ethnic based regional administrations in Ethiopia. It borders Djibouti and Somaliland to the north, Somalia to the east and south as well as Kenya to the south-west.

1 Corresponding author: Abdirahman A. Muhumad (Lecturer), Jigjiga University, College of Social Sciences and Humanities, Sociology Department, Jijiga, Ethiopia. E-mail: amuhumad@jju.edu.et ORCID: 0000-0003-4001-9868

To cite this article: Muhumad, A. A. (2019). Impediments to civil registration: The case of Somali regional state in Ethiopia. Journal of Social Policy Conferences, 77: 287-306 . https://doi.org/10.26650/jspc.2019.77.0020

CThe Authors. Published by the İstanbul University under the terms of the Creative Commons Attribution License https://creativecommons.org/licenses/by$\mathrm{nc} / 4.0 /$, which permits unrestricted use, provided the original author and source are credited.
} 


\section{Impediments to Civil Registration: The case of the Somali Regional State in Ethiopia}

The lack of accurate and reliable population data makes policy formulation, development planning and political endeavor difficult. It is a must for any nation of the world to have clear-cut information about its population, without which sustainable and holistic development is not attainable. Thus, population census, sample survey and vital event registration are the three major sources of demographic data. The census and sample survey methods of population data collection are not satisfactory because they are not continuous processes, and responses tend to be inaccurate. While sample survey and population census are important alternate sources of information, they are also recognized to be more expensive and not cost effective (Plan Ethiopia and the African Child Policy Forum, 2005).

Civil Registration is defined as "the continuous, permanent, compulsory and universal recording of the occurrence and characteristics of vital events pertaining to the population, as provided through decree or regulation in accordance with the legal requirements in each country" (UNSD 2014, p. 65). It is the act of recording and documenting vital events in a person's life, such as birth, marriage, divorce, adoption, and death, relatively satisfactory in terms of data quality and cost efficacy when compared to census and sample survey, and is a fundamental function of governments (WB \& WHO, 2014).

From civil registration records, vital statistics (VS) on vital events (births, deaths, causes of death, fertility and mortality) can be produced for policy and planning. If civil registration systems are robust, and data is complete, it is generally accepted to be the preferred source of vital statistics, due to the ongoing and timely collection of data, and the ability to include information related to the cause of death. In a nutshell, vital statistics are the result of functional civil registration systems (WHO, 2012).

In spite of the multi-faceted significance and use of vital events registration (civil registration), the status of registration in many nations of the world is not encouraging. Worldwide, there are an estimated 625 million unregistered births for children between $0-14$ years of age (WB, 2015), around $1 / 3^{\text {rd }}$ of all births and half of all deaths go unregistered and unrecorded respectively (WHO, 2017), more than one billion have no legal and identity documents 
and, therefore, are deprived of their rights, access to services and participation in governance and economic development.

Low and middle-income countries have a high number of unregistered children, resulting in a higher "scandal of invisibility" in these countries (Setel, et al., 2007; UNICEF, 2013). According to UNICEF, sub-Saharan Africa has the largest number of unregistered children, with 85 million unrecorded births. To put it differently, only 44\% of births in Sub-Saharan African nations are registered. In some of the Sub-Saharan African countries, less than one in five children have had their births recorded (UNICEF, 2013)

Despite the fact that civil registration is featured in the sustainable development goals (more than $1 / 3^{\text {rd }}$ or $67 / 230$ of the indicators outlined SDGs require data generated by functional civil registration to measure the progress) and reliable, as well as comprehensive civil registration systems are essential for production of vital statistics, a basic component of good governance, and many other health and population indicators, civil registration and vital statistics systems and data are at their infant stages, if non-existent, in terms of completeness, in many developing countries (WB, 2017; UN System Task Force, 2013; WHO, 2012). Over 110 low and middle-income countries lack functional civil registration systems.

Challenges to functional civil registration system and data include, among others, political and administrative barriers (lack of government commitments), lack of awareness on the significance of birth registration, lack of value for birth registration, geographic barriers, economic barriers (limited financing and funds), legislative barriers, cultural factors and discriminatory laws and practices, which are broadly categorized as the demand and supply side barriers were among the key obstacles identified as barriers to functional CRVS systems (Plan International, 2012; UNICEF, 2013; WB\&WHO, 2014).

Ethiopia is one of the sub-Saharan countries with the lowest birth and other vital events registered. Less than $10 \%$ of its children under the age of 5 have their births registered. The country, however, faces several challenges regarding birth and other vital events registration, including a larger proportion of rural populations, administrative structures, infrastructure, information education and communication (IEC), institutional capacity, meager cooperation among stake-holders (inter-operability), and other challenges (WHO, 2014). 
According to Ethiopian Demographic and Health Surveys (EDHS), the Somali Regional State of Ethiopia has the lowest level of birth registration records, with only $1 \%$ of its children under the age of 5 having their births registered (CSA \& ICF 2016)

Therefore, this paper aims to address the impediments to functional civil registration system in the Somali Region of Ethiopia, while recommending better ways forward to improve the current situation of a vital events registration system in the region.

\section{Research Questions}

The paper aims to answer the following research questions

1. What is the current status of civil registration in the Somali region?

2. What are the challenges/impediments to a functional Civil registration in the Somali region of Ethiopia? and

3. What can be done to improve the current situation of the civil registration system in the region?

\section{Methods and Materials}

In order to capture large amounts of data at relatively low cost in a short period of time, and effectively meet the objectives of the study and offer multifaceted descriptions on the impediments to a civil registration system, a cross sectional qualitative design was employed. The design is used due to its potential to describe and display the situation as experienced by the informants in 'fine-tuned detail', and in the informants' own terms, by offering the opportunity to 'unpack' issues, to see what they are about or what lies inside (May (ed. 2002)

To answer the above-mentioned research questions, a guided interview for selected key informants was the main source of primary data for the study. The interview was conducted with 20 selected key informants from concerned government authorities: 6 from the Regional Vital Events Registration Agency (RVERA), 4 from the Regional Bureau of Health $(\mathrm{RBoH})$ and 10 from the Jigjiga Municipality Office (including 6 informants from three Kebeles ${ }^{1}$

1 Kebele is the lowest or smallest administrative structure in Ethiopia, 
under the municipality office). Informants were purposively selected, and the interview took place in their respective offices. Other secondary data employed included civil registration documents, Federal and regional vital events registration agency reports, articles, published and un-published materials, etc.

\section{Literature Review}

\section{Definition of the Concepts}

The United Nations defines civil registration as universal, continuous, permanent, and mandatory recording and documentation of the occurrence and characteristics of vital events such as births, deaths, marriages, divorces and annulments, adoptions, and legitimations, according to the legal and regulatory requirements in each country (UN, 2001, p. 50). Civil registration, compared to other sources of demographic data, is the best source of reliable vital statistics that covers and generates population statistics on a continuous basis. In a contemporary society, state building starts with the establishment of civil registration systems that are critical tools for making every life count. However, because of their incomplete and inadequate civil registration systems, many countries cannot draw upon reliable and accurate vital statistics. A report on Asia and the Pacific area indicates that about 135 million children under the age of five do not have their births registered, and 9 out of 10 people live in countries with unreliable death statistics (UN ESCAP, 2014).

\section{Uses of Civil Registration}

Civil registration is used for various purposes ranging from administrative to individual protection purposes. Administrative-wise, civil registration is used by decision makers to generate sound and timely statistics for policy development. Functional and complete civil registration systems that record vital events inform socio-economic planning across public and private sectors including health, education, employment, finance and economic planning, industry and trade, urban planning, social insurance, environment and others. The health sector has a particularly strong need for functional civil registration and vital statistics systems. For instance, tracking the progress of strategies to reduce the levels of child, maternal and disease-specific mortality and to address inequalities in all these areas requires reliable, continuous and timely 
data on age and cause-specific mortality. Similarly, monitoring the spread and distribution of noncommunicable diseases can only be achieved with reliable vital registration systems that count all deaths, and reliably certify their causes (Forrest E, 1982).

Legally, civil registration documents and records provide a legal proof of identity, death, origin and marriage. Birth registration records are used to provide legal proof of identity and other important civil statuses, which are used by individual citizens to affect a wide variety of rights which the person might be entitled to. Similarly, death records provide legal evidence of the marriage, claims to inheritance, property, insurance benefits and the legal right of a spouse to remarry. Marriage and divorce records are essential records for family rights protection, establishing entitlements for inheritance rights, alimony and the right to remarry (FDRE, 2013).

Statistically, vital statistics are derived from civil registration systems and provide an adequate information base for a country's population. Without functional civil registration system and vital statistics, effectively planning for social development including health care, family planning, education, housing, social security, economic development and other services will not be possible. Accurate and reliable data is essential for proper planning for the needs of the community, particularly for health and education facilities, as well as for housing and the labor market. This information can be generated through civil registration and vital statistics systems which can also provide data for comparison and evaluation of differences among regions, between zones and Woredas $^{2}$ (districts) within a region, and at the international level between countries (Ibid).

\section{Challenges to CRVS}

The International Institute for Vital Registration and Statistics outlined seven major obstacles to civil registration in addition to the lack of funds, which appears to be almost universal. These were (1) failure to provide by law for an autonomous, central registration authority, (2) failure to make registration compulsory, (3) lack of appreciation among high-level

2 Woreda (in Amharic) or district is third level administrative divisions of Ethiopia. The first administrative level is Regions or states (Kilil in Amharic) and the second is zones or zonal administration. Woredas are further sub-divided into a number of neighborhoods (Kebeles in Amharic) which are the smallest administrative units of local government in Ethiopia. 
governmental officials of the need for vital records and vital statistics, (4) lack of registration services in remote areas of the country, (5) delayed (late) registration, (6) lack of qualified staff and (7) lack of motivation among the public to register (Forrest E., 1982). Of these, the lack of an autonomous central registration authority, lack of appreciation of the need for vital records and statistics among officials, and failure to motivate the public to register have the greatest impact in developing countries.

In general, the major obstacles to civil registration can be categorized into two major categories: these are the demand side obstacles and the supply side obstacles to civil registration.

\section{Demand Side Obstacles}

Demand-side obstacles include, but are not limited to, lack of awareness on the significance of registration. A significant number of people around the world are not aware of the importance of birth and death registration for them, their families and the entitlements that comes with them (WB-WHO, 2014). Other obstacles related to the demand side include access (related to process and fees) difficulties; discriminatory laws that particularly affect unmarried women and minority groups; lack of value for civil registration which can be clearly seen from the difference between birth registration and immunization coverage or primary enrolment rate in many countries of the world, as parents see incentive in immunization and education more than in civil registration (Plan, 2014)

Simplifying the process of civil registration service provision increases the coverage of civil registration. In the meantime, the backlog of unregistered children can be reduced through registration at schools.

\section{Supply Side Obstacles}

There are unique, regularly clashing, lawful structures that govern the organizations accountable for CRVS administrations, for example, the health, civil registry and statistics agencies. Numerous nations have troublesome methodology and non-institutionalized frameworks prompting perplexity with respect to what people need to do or display. Supporting documents might be requested, regardless of whether it is or not lawfully commanded, for example, birth certificates requiring confirmation of parents' or guardians' citizenship (WB-WHO, 2014) 
Key stakeholders that run CRVS systems might also lack the important skills necessary for operating the system. Some challenges can be overcome through building the capacity of the existing staff while others require special initiatives, including expanding the size of the statistical profession (Thabane, et.al., 2008) and putting wide and regional networks of civil registrars in place.

Inadequate policies, limited funds and staff (as well as staff capacity), and poorly managed vital events registration systems are the result of poor government commitment/political priority. There has been limited support for strengthening the civil registration system (as a whole), other than focused supports (such as birth registration) from some international organizations. For that reason, civil registration and vital statistics is seen as a "donor orphan" (Forrest E., 1982). However, resource mobilization and proper budgeting for maintenance and functionality of the system is key to ensuring accurate population information.

\section{Lack of Integration and Coordination}

Civil registration is the responsibility of number of ministries and departments, including health and statistical offices, and interoperability, as well as coordination of these departments, is key to the functionality of the system. However, integrating different components of civil registration remains a challenge across many government departments. Division of labor (assigning clear responsibilities within the CRVS systems) and ensuring that there is no duplication or gaps during the registration lifecycle is the first challenge. Some basic activities, such as involving the national statistics agency during the process of designing a new birth certificate form, can greatly enhance the effectiveness of the civil registration system. Existing lack of integration and interoperability between key stakeholders (health, education and civil registration) is also mirrored in the international statistical systems, where efforts have been made to better support the needs of developing countries (World Bank, 2004).

\section{Types of Civil Registration}

According to the International Institute of Vital registration and Statistics, there are two, broad, types of registration systems: Passive registration systems and active registration systems (Forrest E., 1982). The most common type of 
registration system practiced in Africa is the passive registration system. In the passive registration system, a civil registrar sits in the civil registration office, and waits the informants to come and register their vital events. In such a system, awareness of the public on the significance of registration, and willingness of government institutions to collaborate and share information are crucial.

The passive registration system is appropriate in urban and/or settled communities where there is no problem of accessibility to registration centers and transportation. In addition to this, people understand the value of vital events registration documents since they are asked to present them in many occasions to get services. For instance, they are asked to provide a birth certificate to acquire nationality documents, or for first admission of their children to school, and many other services (Ibid).

However, in rural areas of Africa, there is the challenge of access to transport facilities and distance which hinders them to travel to the civil registrar's office, which can be located kilometers away from their residence. This causes the problem of inertia, as the significance and uses of vital records are not clear and self-evident to such people. To put it in another way, vital records have virtually no use for these people. In such an environment, a passive registration system would be very difficult. if not impossible. An active registration system is suggested in such situations to improve the coverage of civil registrations. Through an active registration system, the civil registrar goes around the surrounding areas (villages) to capture the vital events that have occurred, instead of waiting for informants to come and register. Village administrators, school teachers and directors, health care professionals and other local government members are used to either notify vital events to the civil registrar, or directly report vital events to the nearest registration centers (Ibid)

\section{Civil Registration in Ethiopia}

In Ethiopia, population and housing censuses and household surveys remained as the primary source of data on demographic, social and economic matters, and on human settlements for more than five decades (Plan, 2005). The lack of a legislative framework and specific structures, meant the effective registration of children at birth, in the past had contributed to the country's low achievement in birth registration. Accordingly, the Federal Democratic 
Republic of Ethiopia (FDRE) issued the Registration of Vital Events and National Identity Card Proclamation No. 760/2012 which is a comprehensive and compulsory law on registrations of vital events in Ethiopia (FDRE, 2013)

The country, however, faces several challenges with regard to birth and other vital events registrations, including a large, mainly rural population, and highly decentralized administrative structures. Other challenges that need to be addressed include the infrastructure, as the lowest administrative structures (Kebeles) require registration equipment and supplies, including safe storage for registration records; Information, education and communication to effectively inform and educate the public on the benefits of registration of vital events and the obligation to do so; capacity building to ensure a sustained delivery of services and quality, and a continuous flow of data (Ibid).

The government aims to establish a fully functioning Civil Registration of Vital Statistics by 2020. However, bearing in mind the constraints, it has opted for a scale-up strategy for implementation, rolling out comprehensive CRVS incrementally as basic services, such as power supply, communications and road networks become sufficiently developed to enable the smooth flow of registration documents between vital events registration offices at all levels. The current level of these services would not deter the implementation of a paper-based civil registration, although it could determine the pace of progress towards automation of the system (WHO, 2014).

\section{Analysis and Discussion}

\section{Current State of CR in Somali Region}

A comprehensive national civil registration system was launched in the country in 2016, and the government has enacted national Vital Events registration and Publicity proclamation No 760/2004, which was enforced at all regional states, including the Somali region. Pursuant to this proclamation, the government has established a vital events registration agency by decision of the council of ministers, regulation No. 278/2005, which is accountable to the ministry of justice.

Cognizant of civil registration system's key role in planning political, social, and economic developments, in providing various socio-economic services 
to citizens and in making the justice administration expedient and effective, the Regional Vital Events Registration Agency (RVERA) was established in all the nine regions and the two city administrations of Addis Ababa and Diredawa, due to proclamation no 760/2012, under its sub article 5. For this reason, the Somali regional state has established the Vital Events Registration Agency, based on proclamation no 137/2014 at regional level. The agency registers births, deaths, marriages and divorces, and gives certificates.

Proclamation 760/2012 was amended in August 2017 (Proclamation No. 1049/2017) to extend the scope of application of the system to refugees and other non-nationals, and entrust the responsibility of notifying community births and deaths to health extension workers.

Regarding the coverage, the Somali Region VERA has undertaken some steps towards realization of the mandate given to the agency. The agency has set up registration offices within the urban and rural kebeles, hired and trained staff at the regional level and at the city administration levels (five out of six city administrations) and raised awareness on the significance of civil registration using regional media (radio and TV). However, according to the informants interviewed, out of the 11 administrative zones of the Somali region, 4 zones (Fafan, Jarar, Sitti, and Erer) have been partially reached (There are some woredas that have not been reached within these zones). Out of the identified 1396 registration centers (kebeles) in the region, 282 Kebeles have been reached, trained and registration documents delivered. It is worth noting that, according to the informants interviewed, the registration documents require Amharic language literacy, yet the majority of the Kebele managers that the documents have been entrusted to, do not write the Amharic language, and no regular monitoring and follow-up activities have been conducted in the majority of these Kebeles, except the accessible and nearby Kebeles located in and around Jigjiga (the main town in the region). This demonstrates the poor coverage of the registration system, and the need for improvement in the civil registration system of the region.

On the civil registration progress, from the registered vital events so far, the majority of them were registered in urban localities (main cities). For instance, according to Regional Vital Events Registration Agency (RVERA) reports, from November 2017 to March 2018, out of 1680 births registered, 1606 were registered in urban localities, and only 74 births got registered in 
rural areas, out of 251 marriages registered, 243 were in urban localities. In addition to this, the number of late registrations and backlog is way higher than timely registered events, however, there are gaps in data pertaining to registration time; the number of timely, late and backlogs. Most people come and get their vital events registered only when a need arises (for passport, inheritance, and getting other benefits that require proof of registration certificate). Further full data collection and analysis will help us to get the right picture on this matter.

On coordination activities (inter-operability), informants mentioned that there is weak coordination between RVERA and the regional health bureau, and there is no coordination between RVERA and other stakeholders (Education, ARRA and Central Statistical Agency). As a result of the mandate given to the health partners by the proclamation, the regional health bureau has prepared, printed, disseminated and distributed birth and death notification documents to a few public health facilities. The bureau has collected reports, not the records, on an irregular and unreliable manner. However, health facilities do not regularly report the births and deaths registered through a notification document, which brings the reliability of the data under question. In addition, the link between health facilities and RVERA is still very weak. According to the informants interviewed, very few of the births and deaths notified by health facilities get registered and certified due to various reasons. For instance, only 150 births out of 2123 births notified by the health facilities during Nov 2017 to March 2018 got registered and certified. Among the reasons mentioned by the respondents, distance between the health facilities and Kebeles, lack of clear directions from health-care professionals on how to get the birth certificate, lack of value for birth registration, lack of awareness on the significance of these documents and Amharic language illiteracy of the Kebele managers, were some of them.

\section{Challenges to Civil Registration in the Region}

As mentioned in the earlier section, the regional VERA has taken considerable steps towards the realization and cascading of civil registration system towards the Kebele level (the lowest administrative unit). However, the civil registration system of the region is very weak, even compared to the other regions of the country. According to a Federal Vital Events Registration 
Agency (FVERA) report (January 2018), the civil registration coverage of the region was only $9 \%$ compared to other regions, as indicated in the chart below.

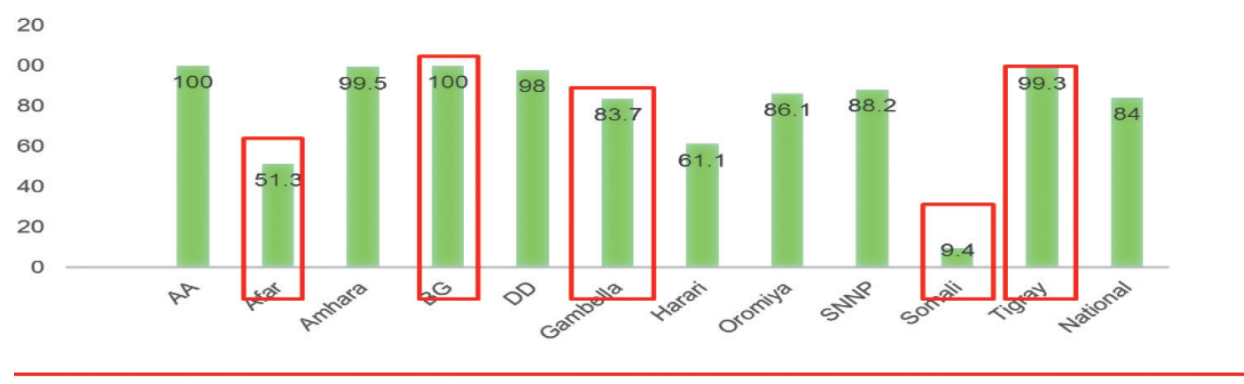

Coverage of civil registration in Ethiopia Source FVERA, 2018

As in many parts of Africa and Ethiopia, the development of viable and strong civil registration systems in Somali region has been beset with many problems. The following paragraphs elaborate some of the challenges/ impediments to civil registration in the region.

\section{Financial, Human and Logistical Challenges}

Despite being a universal problem, the allocation of insufficient funds by the national governments lies at the heart of the challenges to civil registration systems in many underdeveloped regions of the world. The Somali region is by no means the exception to this case. The Somali region government allocates the lowest budget to RVERA, as indicated in the agency reports. This contributed to poor office standards (Kebeles) and the inability of the agency to recruit enough staff, furnish offices with the minimum necessary office materials and cascade their work beyond certain areas. Pertinent to, and as result of this, the agency faces serious challenges on logistics and human resources, and this is evident in all the registration centers (kebeles). The lack of quality data due to incompetent staff, and the lack of regular monitoring and reporting of the registration sites is both the outcome and associated challenge. According to the informants interviewed, it is mainly with support of UNICEF that the agency could deliver registration documents to some of the kebeles in four zones of the region. 


\section{Political/Government Commitment}

Poor or lack of political/government commitment and priority has resulted in inadequate coordination and poor, if nonexistent, interoperability among the key stakeholders on civil registration works. Despite the health and statistical uses of civil registration, there is a clear lack of integration between civil registration, health, education, statistical authorities and other key stakeholders. Health facilities (public and private), according to proclamation number 760/2012, should notify both births and deaths, keep and collect records, and report to the vital events registration agency. Despite these mandates, civil registration is not linked and integrated into health facilities, and birth/death notifications by the health facilities do not serve for their intended purpose.

\section{Lack of Value and Low Awareness}

Lack of knowledge on the benefits and the process of civil registration among the public is also another challenge to civil registration in the Somali region. According to the World Bank, many people are not aware of the importance of civil registration for them and their families, and the implications that this has for access to core government services (WB-WHO, 2014). This is the case in the Somali region, where there is an evident lack of interest among the public to register their vital events. Related to this is that there is no value for civil registration and therefore, people do not bother going through the process because they do not perceive any benefit in it. Birth registration in the region, according to Ethiopian Demographic and Health Surveys EDHS, was only $1 \%$, whereas the immunization coverage was $22 \%$, and primary education enrollment was $84.6 \%$ (CSA \& ICF 2016). This demonstrates that parents understand the benefit of immunizing their children, but fail to report new births to the nearby Kebeles since they do not see any incentive in doing so.

\section{Registration Process}

The registration process is another impediment to the civil registration system in the region. There are official fees associated with the registration of vital events as per the internal directives of the agency, and a need for the presence of both parents for birth registrations. Lack of a perceived benefit 
of the registrations, coupled with official $\mathrm{fees}^{3}$, fines for late registrations, presence of both parents for birth registration, and bureaucracy in the certification process dwindles the interest of the public to get registered and certified. In addition to this, according to the informants interviewed, bribes and un-official payments associated with the certification process has been reported to be other impediments to the system. It is too costly for most of families to register their vital events and therefore discourages them to do so.

\section{Mobile Nature of Pastoralists}

Pastoralism is the main livelihood pattern of the region and the majority of the dwellers in the region are pastoralists (they move from one place to another in search of water and pasture and in doing so, do not have a permanent settlements). In Ethiopia, a mix of active and passive registration type is used. The registration documents are not taken out of the registration centers, but through a network of health, traditional birth attendants and other social networks, new vital events are notified to the Kebeles. However, these systems are not effective in the Somali region at their best and have not worked at all for several reasons: the distance of the kebele from the villages, transportation, the mobile nature of the pastoralists, lack of incentive (value) for registration, and the official fees for registering vital events.

What can be done to improve the civil registration status in the Somali region?

Since its establishment, regional vital events registration has made progress on the registration works in the region. However, the agency has faced serious challenges, as mentioned in the above section. Therefore, the researcher recommends the following issues for a functional civil registration system that would improve registration rates in the Somali region:

There is a need to use computer technology, and make civil registration in the region computerized to improve data storage and production of information on the registered vital events for various administrative, health and statistical uses.

3 According to the internal directives of the office, people must pay amount of fee ranging from $50-200$ Birr (Ethiopian Currency) which is roughly equivalent to $2-70 \$$ to get their vital events registered and certified. Timely birth and death registrations are 50 Birr and 25 Birr respectively. Whereas marriage and divorce registration and certifications range from 100Birr - 200 Birr. In addition, there are penalty fees imposed late registrations and backlogs. 
The vital events registration and national ID proclamation No 760/20014 gives the mandate of birth and death notification to the health ministry and bureaus at the regional level to takecare of it. However, there are visible gaps in the inter-operability and coordination among the key stakeholders. Within both regional and federal governments, effective vital events registration system calls for the attention, and is the responsibility, of a number of government organs: health, education, city administrations and justice organs, at the federal and regional levels. Therefore, improving the interoperability and coordination between these entities is vital, and specific mandates within the civil registration work should be given to each stake-holder, strong and well-coordinated taskforces shall be established and Terms of References (ToRs) on the roles and responsibilities, as well as clear guidance on monitoring and reporting should be prepared. According to the WB \& the WHO, coordination and communication among key stake-holders of civil registration systems is key to the performance of the system (WB-WHO, 2014). However, it is important to mention that this will need a political/government priority and commitment.

The registration process needs to be simplified through legal reforms. The process and providing a vital event registration service within the existing structures, without necessarily establishing new ones, can improve and increase the registration coverage (Tom J, 1981). Such efforts will eliminate some features of the vital events registration procedures, that discourage people from registering their events. In line with this, official and unofficial fees should not be levied for registration as well as certification. Moreover, measures shall be taken by government authorities to eliminate corruption (bribery) within the system. Pastoralists, as well as settled communities in the region, shall be allowed to register their events in case both parents are not available to remove a possible barrier to registration.

The value for civil registration shall be carefully thought out, and vital events certificates must be made obligatory pre-requisites for various social services to create demand for vital records. For instance, vital records shall be necessary to access certain services, for example, when children are first admitted to school, to attest to their dates of birth, and acquiring travel papers to prove nationality. The same can be true if immunizations and birth registrations are linked.

Passive registration is not a solution for a mobile population like the Somali pastoralists, nor does the system of using involuntary social networks 
(Community groups, traditional birth attendants etc) to notify births, where the public must walk kilometers to get their events registered. For Somali pastoralists, active registration or a similar system will work better. Assigning a dedicated (full time) civil registrar at the Kebele level would yield better results than using the Kebele chairman as a civil registrar. The civil registrar should visit areas under his/her kebele periodically, say monthly, to investigate and register what vital events have occurred since his last visit and, at the same time, use the visit to raise the awareness of the public on the significance of civil registration. In this way, vital events, particularly births and deaths, can be registered timely, and delays can be avoided. For the back-logs of unregistered children, registration at schools can be one of the best ways to get them in the picture. According to Ethiopian Demographic and Health Surveys. EDHS, the primary education enrolment rate in the country is $84.6 \%$ (CSA \& ICF, 2016). This can uplift the registration of unregistered children, both in rural and in urban areas, within a short period of time.

Lastly but not the least, a functional civil registration system needs a functional government system down to Kebele level. Despite the weak and porous government structures at most of Kebeles in the Somali region, the vital events registration agency faces serious shortages of staff at the woreda and the city administration levels. Therefore, staff shall be recruited as per the agency structure. Trainings and all the necessary pre-requisites shall be given to these staff to handle their responsibilities. Enough budget should also be allocated for civil registration in the region.

\section{Conclusion}

Strengthening civil registration systems is acknowledged as the way to establish fundamental human and civil rights. Despite the multifaceted importance of civil registration, civil registration systems in Sub-Saharan African nations is very weak, if nonexistent. The same is true for Ethiopia. Major and significant actions on civil registration in Ethiopia and in the Somali region have been taken only recently. While efforts have focused largely on the improvement of a civil registration system for births, deaths, causes of death, marriage, and divorces, it is also important not to turn a blind eye to the mutual benefit in strengthening systems such as health and ID systems in tandem. 
Several efforts have been made by the recently established federal and regional vital events registrations, both at the federal and regional levels. Yet, they face a number of challenges that hinder a functional civil registration system. Financial and human resource challenges, logistical problems, the mobile nature of pastoralist population, a lack of strong coordination, a lack of political/government priority and commitment, a lack of knowledge on the significance of civil registration and a lack of value for civil registration are among the key challenges that hinder a functional civil registration system in the Somali region.

Improving the link between vital events registration and the key stakeholders (health, education, justice, city administrations and others) is key to a functional civil registration in the region, and this action calls for a strong political commitment. Other recommendations include removing barriers surrounding to registration process in the region: removing official and unofficial fees for the service etc., assigning a dedicated civil registrar instead of using the Kebele manager as registrar, and permitting the civil registrars to visit the areas under his/her kebeles on a monthly basis to register and deliver the awareness message would also boost the registration rates in the region. Scrutiny on value for civil registration is needed. Compared to immunizations and primary education enrolments, civil registration is lagging way behind, yet, there is a way to link civil registration to these services.

Improving civil registration through a civil registration and vital statistics information system is vital, and a potential area for research. The paper focused on the impediments to current civil registration system in the region, and ways to improve it in coverage and quality. However, the need to modernize the registration through digital systems, the cost of civil registration in the region and linking civil registration to vital statistics is an area that calls for the attention of researchers.

Grant Support: The author received no grant support for this work. 


\section{References}

Central Statistical Agency (CSA) [Ethiopia] and ICF. 2016. Ethiopian Demographic and Health Surveys (EDHS), 2016, Addis Ababa, Ethiopia and Rockville, Maryland, USA: CSA and ICF.

Civil registration and Vital Statistics (CRVS) and Sustainable Development Goals (SDGs), 2016, Advocacy material. https://www.getinthepicture.org/resource/civilregistration-and-vital-statistics-crvs-and-sustainable-development-goals-sdgs

FDRE (2013). Towards sustainable vital events registration and vital statistics systems of Ethiopia: Strategy and Action Plan July 2013 - June 2018.

Federal Vital Events Registration Agency (FVERA) (2018), Mid-Year Vital Events Registration Report, Addis Ababa.

Forrest E. Linder, (1982). Improving vital registration systems in developing countries. Technical paper No 20, International Institute for Vital Registration and Statistics.

Handbook on Training in Civil Registration and Vital Statistics System; Studies in Methods, Series F, No. 84; United Nations, New York, 2002 (Module 2) http://unstats. un.org/unsd/ publication/SeriesF/SeriesF_84E.pdf

IDRC Canada, Current state of CRVS: an overview, Produced for the international conference on CRVS innovations, Ottawa, Canada, February 27-28, 2018.

May, T. (2002).Qualitative research in action. New Delhi: SAGE Publications.

Plan Ethiopia and the African Child Policy Forum (2005). Perception and Practices: A review of birth registration in Addis Ababa and the regional states of Oromia, Amhara, SNNP, Ethiopia.

Plan International. "Birth Registration: Resources.” https:// plan-international.org/whatwe-do/child-participation/birth-registration/resources. Accessed May 12, 201.

Proclamation no.1049/2017, Vital Events Registration and National Identity Card proclamation (amendment) proclamation.

Regional Vital Events Registration Agency (RVERA) (2018), nine months report (July 2017 - April 2018), Jigjiga, Ethiopia.

Setel, P. W., Macfarlane, S. B., Szreter, S., Mikkelsen, L., Jha, P., Stout, S., AbouZahr, C. (2007) A scandal of invisibility. Making everyone count by counting everyone. Lancet, 370, 1569-1577.

Thabane, L., Chinganya, O., \& Ye, C. C. (2008). Training young statisticians for the development of statistics in Africa. African Statistical Journal, 7, 125-148.

Toma J. M. (1981), Methods and Problems of Civil Registration Practices and Vital Statistics Collection In Africa, Technical paper No 16, International Institute for Vital Registration and Statistics.

United Nations (UN). (2001). Principles and Recommendations for a Vital Statistics System Revision 2, United Nations, New York, 50. 
United Nations Statistics Division (UNSD). (2014). Principles and Recommendations for a Vital Statistics System. Revision 3. New York: United Nations, 65.

UNICEF (2017). Specific domains of respectful newborn care: the role of Civil Registration and Vital Statistics systems, PTB TWG-ICS- Session 3, New York.

United Nations Children's Fund (UNICEF), A Snapshot of Civil Registration in SubSaharan Africa, UNICEF, New York, 2017.

UNICEF (2013). Every child's birth right: Inequities and trends in birth registration. New York: UNICEF.

UNICEF (2013). A passport to protection: a guide to birth registration programming. UNICEF, New York, p. 11

WHO (2012). Civil Registration and Vital Statistics. WHO-FIC information sheet.

WHO (2013). Civil Registration and Vital Statistics: Challenge, best practices and design practices for modern systems, Geneva.

WHO (2013). Strengthening CRVS Systems through Innovative Approaches in the Health sector. WHO Geneva.

WHO (2014). Civil Registration and Vital Statistics Investment Planning: Report of a Technical Consultation. Addis Ababa, 28-29 April 2014.

WHO 2017 World Health Statistics. WHO Geneva.

World Bank and World Health Organization (WB-WHO) 2014. Global CRVS Scaling Up Investment Plan 2015-2024. http:/www. world bank.org/ en/topic/health/publication/ global-civil-registration-vital-statistics-scaling-up-investment.

World Bank Data Bank. World Development Indicators. Available from: http:// http:// databank .worldbank .org /data/reports. 